\title{
Design of Visual Education Resource Library Based on 3D Modeling
}

\author{
$\underline{\text { https://doi.org/10.3991/ijet.v13i11.9609 }}$ \\ Dongmei Xia ${ }^{(\varpi)}$, Jing Li, Liang Zhou \\ Chongqing Institute of Engineering, Chongqing, China \\ Chinese Culture Animation Research and Development Communication Center, Chongqing, \\ China \\ dongmeixia2193@21cn.com
}

\begin{abstract}
At present, the problems in the design of 3D visualization resources, such as less involved in interaction design, no unified design standards and norms, lack of effective innovation guidance mechanism and no unified evaluation system. In order to further promote the deep integration of information technology and teaching resources, the design and application of $3 \mathrm{D}$ visualization resources in teaching scenes are studied. Take the amino acid of biology compulsory textbook in the first year of high school as an example; according to the design scheme, the $3 \mathrm{D}$ visualization resources are produced. The main processes include selection of production tools, preparation and production of materials, writing of scripts, design of learning interfaces, design of interactive logic relations, control and output of programs, and then the relevant results are displayed. Then, the $3 \mathrm{D}$ visualization resources are applied to the future classrooms equipped with the starC electronic double board and the group touch screen, and the teaching effects are analyzed and evaluated. The research shows that the $3 \mathrm{D}$ visualization resources can effectively improve the students' interest in learning and help students understand the knowledge.
\end{abstract}

Keywords-3D visualization; teaching resources; starC; teaching effect

\section{Introduction}

In the education virtual reality, with the rapid development centered on virtual reality technology, users use computers to simulate the real environment, observe complex things, and use computers and other devices for interactive operations, which are getting more and more attention. As the development direction of virtual reality technology, 3D visualization is widely used in geological depiction, military applications, digital cities, medical imaging, national defense technology, simulation training and education. The teaching resources are also beginning to develop in a more vivid and threedimensional direction. On January 23, 2017, Didi-Capital released their “Augmented Reality and Virtual Reality Report in 2017", which predicted that the global VR/AR market will have $\$ 108$ billion in revenue by 2021 . 
The rapid development of virtual reality technology has also brought new innovations to teaching resources. The teaching resources have changed from traditional textbooks to later multimedia materials. The teaching resources in the future classrooms have begun to transform into three-dimensional visualization resources. The development trend of classroom teaching in the future is to enhance reality technology and carry out gamification learning. Three-dimensional visualization resources have an important impact on the teaching and learning of teachers and students. In teaching activities, teaching resources are indispensable, and teaching resources directly affect the effect of teaching activities, which means that 3D visual teaching resources play an important role in the future classroom.

At present, the design of 3D visualization resources has made great progress in hardware, but there are still some shortcomings in interaction design. In the teaching scene, the design and development of 3D visualization resources needs to be greatly improved. In teaching activities, common teaching resources such as PPT resources use pictures and texts for classroom teaching. The teaching resources are not vivid enough to attract students' interest in learning. The participation of students is not high. Starting from the specific application, taking "The amino acid and protein" in the biology as an example to carry out specific research, combined with the specific needs of biology research group in high school, design and develop relevant resources, and apply and observe results in the specific classroom. By evaluating and summarizing the application effects in the actual classroom and giving relevant suggestions, it provides ideas for the future development of $3 \mathrm{D}$ visualization resources.

\section{Literature review}

The earliest classroom teaching resources are mainly paper-based printing materials. Teachers use traditional textbooks and teaching aids in class, and they complete a lesson with blackboard-writing. The teaching resources of the classroom mainly rely on traditional teaching media such as textbooks, blackboards, wall charts and physical models. The knowledge of students can only be obtained through teacher teaching. Since the development of e-education in the 1930s and the rapid development of computer technology and multimedia technology, the forms of classroom teaching resources have gradually become rich and diverse. The digital teaching resources of multimedia platforms have changed the traditional way of relying solely on paper textbooks and blackboard teaching [1].

The teaching resources are mainly PPT produced in the form of words, pictures, sounds, animations, etc. Especially in the classrooms of primary and secondary schools, PPT teaching resources have brought great convenience to the teaching of various subjects. Mott elaborates on the application of resource presentation PPT to the primary school classroom, and the students are full of enthusiasm for completing the teaching tasks such as longshelan and stroke order [2]; Welsby introduces the four principles of PPT courseware application in classroom teaching: the principle of auxiliary, the principle of efficiency, the principle of interaction and the principle of flexibility, flexibly promoting the integration of PPT teaching resources and classrooms, making the 
teaching process more holistic [3]; Wong discusses the new changes that PPT brings to the English class, creates a language teaching environment, and stimulates students' enthusiasm for learning English [4]; Traschütz explores the application of PPT as a tool for screen display in the teaching of various subjects in middle schools [5].

With the rapid development of mobile networks and mobile technologies, electronic textbooks appear in classroom teaching in the form of e-schoolbag. The e-book bag is a holistic learning platform centered on learners, focusing on mobile devices and network resources, and running through pre-class, in-class and after-class. Hansen et al. introduced the development of e-schoolbag in China and the United States and made recommendations on the development of e-schoolbag in China [6]. Ferreira studied the development of electronic textbooks in middle school mathematics teaching, embedding video in e-schoolbag, enabling students to conduct mixed learning [7]. Bolognese et al. identified the standard framework for electronic textbook and e-schoolbag [8].

With the development of educational virtual reality, digital teaching resources have emerged in new forms, and teaching resources have begun to appear three-dimensional resources. The difference between three-dimensional resources and two-dimensional resources is that learners can observe abstract knowledge from multiple angles. The common three-dimensional resources appear in the form of simulation experiment teaching and are often used in experimental classes of physics, biology, and chemistry [9]. The earliest research on simulation experiments was in the United States, which was used in the military field, and then widely used in other fields such as medicine, architecture, games, etc., and gradually became popular in the field of education. In the mid-1990s, Paul et al. at the University of North Carolina School of Education made a practical study of the effects of three-dimensional techniques on the teaching of high school biochemistry. They randomly divided the students into four groups, and respectively adopted the mixed teaching methods of the traditional teaching materials, threedimensional virtual models, physical ball-and-stick models, traditional textbooks and three-dimensional virtual models. Finally, the teaching effect is tested and found that the teaching method can achieve the best with the combination of traditional teaching materials and three-dimensional virtual models in teaching [10]. Although the threedimensional virtual model in Paul's experiment can present the related concepts of abstract molecular structure through the three-dimensional virtual environment, the threedimensional virtual model resource is only the composition of the molecular structure and doesn't make a procedural description and generation of the formation of the molecular structure. There are still shortcomings in students' understanding of procedural knowledge through human-computer interaction.

A virtual experiment software developed by the University of Washington, USA, mainly simulates a chemical reaction system. Students enter a virtual laboratory, wear a helmet, hold a joystick, and operate on related chemical atoms to achieve a chemical reaction between hydrogen atoms and oxygen atoms. The software of the University of Washington is mainly designed for the reaction between some atoms in specific chemistry disciplines. It is used in specialized laboratory scenarios and is not used in specific classroom teaching. It is mainly to train students to learn a knowledge point, and it does not help systematic learning of knowledge [11]. 
With the further advancement of educational informatization, classroom aid has begun to take on new forms: writing whiteboards, electronic whiteboards, and interactive whiteboards. The electronic whiteboard is developed in combination with the function of writing and projecting on the blackboard. The teacher can use the electronic whiteboard for projection, free writing and screen annotation. Interactive whiteboards mainly communicate between electronic whiteboards and computers, first popular in developed countries such as the UK [12].

Kim et al. studied the impact of using interactive whiteboards on the academic performance of seventh-grade students in the process of mathematics teaching. The research was carried out in the way of experimental design. Students were divided into experimental and control groups, and pre-test and post-test were performed on students with measurement tools. The teaching activities of the control group were limited to the use of the blackboard, and the experimental group taught with the interactive whiteboard and blackboard. The research results showed that the use of interactive whiteboard in the process of mathematics teaching had a positive impact on students' mathematics scores [13]. In the field of interactive whiteboard application, the series of research results of the "Sino-British cooperative interactive whiteboard experimental research project" jointly completed by the Distance Education Research Institute of the Capital Normal University, the Beijing Institute of Educational Science and the Beijing Primary and Secondary Schools are more representative. Warner studied classroom interactivity in an interactive electronic two-board environment. The research results showed that compared with the traditional teaching environment, the students in the interactive electronic dual-board environment are more motivated and the learning effect is more significant. Based on the classroom teaching of the interactive electronic whiteboard, the teaching content is presented on the electronic whiteboard. If teachers want to play resources of different format content, they need to switch to other operation windows, which has an impact on the integrity of teaching, and it is not conducive to the systematic implementation of learning in teaching activities [14].

At present, the application of 3D visualization resources in classroom teaching activities is still relatively small, and applications in the field of education include the presentation and transformation of knowledge and helping the team to communicate. The actual development of the case is more of a small case presented separately, and there is no specific study on the research of $3 \mathrm{D}$ interactive teaching resources in classroom teaching.

\section{Scheme for 3D interactive visualization resources in teaching scenarios}

The design of 3D interactive visualization resources is one of the important aspects of effective development of teaching resources. Good 3D teaching resource design can improve the way teachers and students interact with resources in the teaching scene and improve user experience. In view of the problem of "At present, there is no complete experimental site in the teaching process. It can only face boring books and textbooks. There are safety risks of equipment and personnel in the traditional classroom.", in the 
process of designing teaching resources, it is necessary to design and develop teaching resources by means of $3 \mathrm{D}$ virtual tools. By designing $3 \mathrm{D}$ visualization resources with amino acids and peptides as examples, the shortcomings in interaction design can be improved and learning performance can be improved. According to the design principle of $3 \mathrm{D}$ visualization resources, the specific resource design scheme and teaching design scheme of 3D visualization resources in the teaching scene are constructed.

\subsection{Design scheme of 3D visualization resources}

The 3D visualization resource is designed to allow learners to learn in a gamified context. At the time of design, it is necessary to fully consider the three-dimensional structure of resources, the needs of teaching, and the possibility in the specific practice process.

After entering the game, the user will get enough initial gold to buy the basic atom (bullet), and the molecular formula will be displayed in the upper right corner of the screen. After the user is familiar with the molecular formula, they plan the number and type of atoms (bullets) that need to be purchased. Through the shooting of various bullets, the assembly and disassembly of amino acids are carried out, thus increasing the entertainment of resources and enhancing the enthusiasm of students. Finally, through the certain comparison of the total number of gold coins to appear a certain gap, in order to make up for the gap, students will further improve their proficiency in knowledge. A countdown will be displayed in the time bar at the top left of the screen, and settlement will be done as soon as the time is up. After completing a task, the user will get a star and get up to three stars.

The first task is to complete the splicing of basic amino acids (for example, glycine). There will be no prompts for splicing errors during the splicing process. Click the OK button after the entire splicing is completed. If there is a splicing error, the resource platform will prompt an error, but the player needs to find his own mistake. After finding the error, click Retry to restart the game. After the splicing is correct, click the Confirmation button to pop up a dialog box to choose to sell or cancel, and the task button will flash with the word New, prompting to unlock the new task. Of course, players can earn gold coins by completing task 1 multiple times, or they can choose gold coins to reward more tasks.

Click on the task button to enter task 2 . The store will also unlock new bullets (decomposed bullets). Task 2 disassembles the -OH on the carboxyl and - $\mathrm{H}$ on the amino by manually launching the decomposed bullets to achieve dehydration and condensation, forming dipeptides and producing a molecule of water. If it is wrong, the player will need to purchase the decomposed bullets again to disassemble. If it is correct, when task 2 is completed and task 3 is entered, it is also necessary to use the decomposed bullets to disassemble the - $\mathrm{OH}$ on the carboxyl and $-\mathrm{H}$ on the amino and accomplish task 3 in the same way.

Finally, the total gold coins are settled for achievement rewards and star awards. 


\subsection{Scheme of teaching design}

Resources are designed to prepare for teaching activities. In the specific teaching design process, the designed 3D visual teaching resources are introduced for the resource assistant teaching. Taking "master amino acid" as an example, table 1 describes the design scheme of "master amino acid" teaching activities.

Table 1. Design scheme of teaching activity

\begin{tabular}{|c|c|c|}
\hline Type of activity & Activity time & Teachers' activity \\
\hline Situation import & $5 \mathrm{~min}$ & $\begin{array}{l}\text { The teacher shows the students the common protein and allows the stu- } \\
\text { dents to supplement it. } \\
\text { The teacher guides the students to answer, and finally leads out that } \\
\text { amino acids are the basic building blocks of proteins. }\end{array}$ \\
\hline $\begin{array}{l}\text { Collaboration and } \\
\text { inquiry }\end{array}$ & $20 \mathrm{~min}$ & $\begin{array}{l}\text { Display the structural formula of the four common amino acids (gly- } \\
\text { cine, alanine, leucine, valine), observe and answer the basic elements } \\
\text { of amino acids. } \\
\text { Where is the structural formula of different amino acids specifically } \\
\text { represented? } \\
\text { Summarize the structural formula of amino acids. }\end{array}$ \\
\hline Independent study & $10 \mathrm{~min}$ & Teacher inspects and guides students. \\
\hline In-depth study & $25 \mathrm{~min}$ & $\begin{array}{l}\text { The protein is formed by dehydration condensation of amino acid mol- } \\
\text { ecules, and the teacher shows the students a schematic diagram of de- } \\
\text { hydration condensation. }\end{array}$ \\
\hline $\begin{array}{l}\text { Reporting and } \\
\text { communication }\end{array}$ & $20 \mathrm{~min}$ & $\begin{array}{l}\text { Teachers organize various groups of students to display their works } \\
\text { The teacher shows the students how amino acids form proteins }\end{array}$ \\
\hline $\begin{array}{l}\text { Post-class exten- } \\
\text { sion }\end{array}$ & $5 \mathrm{~min}$ & $\begin{array}{l}\text { The teacher arranges small tasks and allows students to use the "master } \\
\text { amino acid" resource platform for assembly and dehydration condensa- } \\
\text { tion exercises. }\end{array}$ \\
\hline
\end{tabular}

\section{Production of 3D interactive visualization resources in teaching scenes}

In view of the problem of "At present, there is no complete experimental site in the teaching process. It can only face boring books and textbooks. There are safety risks of equipment and personnel in the traditional classroom.", in the process of designing teaching resources, it is necessary to design and develop teaching resources by means of 3D virtual tools. Based on the dual-track teaching platform in the teaching scene, it is necessary to design $3 \mathrm{D}$ visualization resources to assist teaching activities. The solution to this problem is to introduce $3 \mathrm{D}$ virtual reality technology and transform traditional teaching content into computer graphical platform resources. Learners can learn anywhere, anytime, without being restricted by time and space. According to the characteristics of 3D visualization resources, take "master amino acid" as an example to construct its production process. 


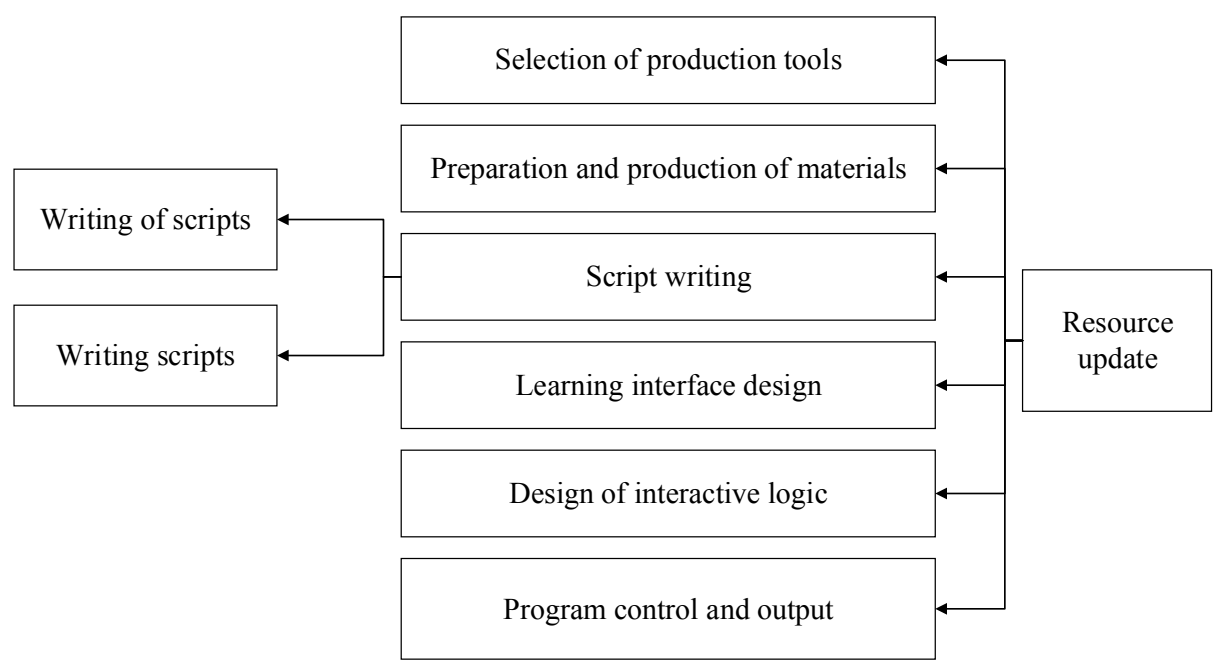

Fig. 1. Development process of 3D visualization resources

\subsection{Script writing}

In the process of making 3D visual resources, script writing includes text script writing and shooting board. According to the needs of teaching practice, text scripting describes the content to be delivered by the designed 3D visualization resources. The shooting board is based on the text script, it designes the specific module structure and function of the 3D visualization resource, similar to the sub-shot script in film and television production. As a direct basis for the production of 3D visualization resources, it is the direct blueprint of the design of learning interface in the next stage.

Take "master amino acid" as an example to write a text script.

Step 1: First select the first atom to emit. Step 2: Select the location where the first atom is to be sent and place the first atom. Step 3: Add the atom to be emitted next and select the position of the covalent bond that activates the atom to be connected, then transmit and connect. Step 4: Repeat steps 1, 2 and 3 according to the structural formula of the amino acid to complete the assembly of the amino acid. Step 5: The assembled amino acids are dehydrated and condensed, and the amino and carboxyl positions of the amino acids are selected for disconnection, then linked by dragging to form a dipeptide and a water molecule. Step 6: Dehydration condensation of the dipeptide and amino acid molecules to form a tripeptide and a water molecule.

Writing scripts

Continue to use the "master amino acid" as an example to write the production script. The script design of the resource platform is shown in Table 2, and the framework of the resource tool is shown in Figure 2. 
Table 2. Script design

\begin{tabular}{|c|c|c|}
\hline Title & \multicolumn{2}{|c|}{ Grasp amino acids } \\
\hline Textbook version & \multicolumn{2}{|c|}{ PEP version of the first year of high school biology compulsory textbook } \\
\hline Authoring Platform & \multicolumn{2}{|l|}{ Virtual equipment factory (PE) } \\
\hline Creative thinking & \multicolumn{2}{|c|}{$\begin{array}{l}\text { Develop a virtual model of amino acids and peptides, and splicing according to the } \\
\text { combination rules of amino acids and peptides, and presenting the splicing activities } \\
\text { in the form of games }\end{array}$} \\
\hline $\begin{array}{l}\text { Content introduc- } \\
\text { tion }\end{array}$ & \multicolumn{2}{|c|}{$\begin{array}{l}\text { The resources enter from the loading page to the main page, the resources can be } \\
\text { learned through the navigation interface, and there are time control areas in each in- } \\
\text { terface }\end{array}$} \\
\hline Applicable object & \multicolumn{2}{|l|}{ Senior 1 student in high school } \\
\hline \multicolumn{3}{|c|}{ System function } \\
\hline 1 & \multicolumn{2}{|l|}{ Construct a single amino acid } \\
\hline 2 & \multicolumn{2}{|c|}{$\begin{array}{l}\text { Dehydration condensation to form dipeptides based on the construction of a single } \\
\text { amino acid }\end{array}$} \\
\hline 3 & \multicolumn{2}{|c|}{$\begin{array}{l}\text { Dehydration condensation of dipeptide and amino acid to form tripeptide (understand } \\
\text { the composition of the polypeptide) }\end{array}$} \\
\hline \multicolumn{3}{|c|}{ Analysis of main modules } \\
\hline Serial number & Module name & Module analysis \\
\hline 1 & $\begin{array}{l}\text { Loading pages of the resource plat- } \\
\text { form }\end{array}$ & Pre-game loading interface \\
\hline 2 & $\begin{array}{l}\text { The main interface of the resource } \\
\text { platform }\end{array}$ & The main interface after entering the game \\
\hline 3 & Exit & Exit a game \\
\hline 4 & Reset & Zero setting, reset scene \\
\hline 5 & Settlement & Settle the big molecules in the game \\
\hline 6 & OK & $\begin{array}{l}\text { Determine the current operation and give a } \\
\text { judgment }\end{array}$ \\
\hline 7 & Task & Unlock more advanced tasks \\
\hline 8 & Store & Provide purchase and sale of atoms \\
\hline
\end{tabular}

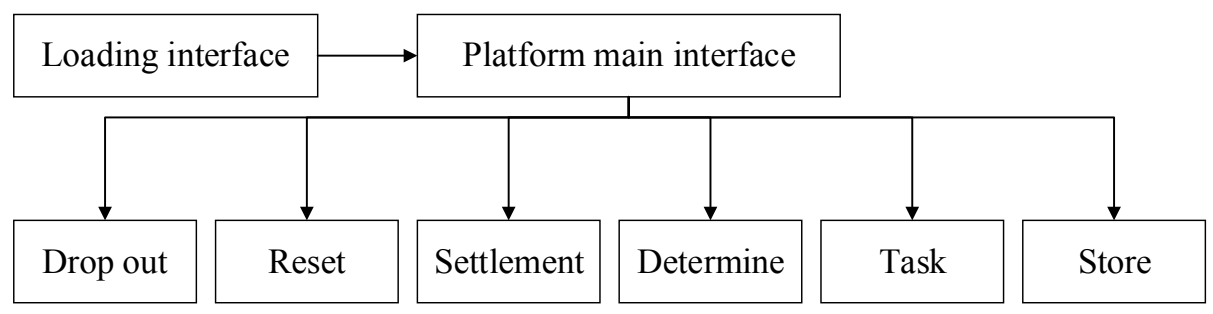

Fig. 2. Framework diagram of the resource tool

\subsection{Design of the learning interface}

The learning interface is the expression carrier of interactive information. The design of the interactive learning interface in the scene mainly includes the design of pictures, words and sounds in the scene. According to the reasonable arrangement layout, the 
two-dimensional objects and three-dimensional objects in the scene are planned and designed to realize the harmony of the scene interface. In the design of the learning interface, it should pay attention to the interface design style, navigation design, and make the user interaction as simple and effective as possible. The principles of designing the learning interface are based on ergonomic standards (ISO 9241), as shown in Table 3 .

Table 3. Principles of the design of learning interface

\begin{tabular}{|l|l|}
\hline \multicolumn{1}{|c|}{ Attribute } & \multicolumn{1}{c|}{ Detailed description } \\
\hline Resolution & Information content is quickly and accurately communicated and identified \\
\hline Interactivity & Facilitating man-machine interaction \\
\hline Simplicity & Users should not bear too much irrelevant information and can operate directly \\
\hline Consistency & Distinguish the key points to meet the actual needs \\
\hline Intergrade & The user's attention can be effectively directed \\
\hline Readability & Information is expressed intuitively \\
\hline Understandability & Information is clear and easy to understand \\
\hline
\end{tabular}

\subsection{Program control and output}

Program control includes control over variables in the scene and function control. Variables are used to record changes in data generated during the interaction to achieve logical control of different events. Function control includes animation functions, string functions, bit arithmetic functions, mathematical operation functions, file processing functions, node functions, database functions, communication functions, character animation functions, edit box functions, etc. Through the control of variables and functions in the scene, the production of the "master amino acid" three-dimensional visualization resource is completed. After the output is completed, the designed resources need to be tested and further modified until it is satisfactory, and the relevant usage rules and guide descriptions are finally formulated.

\section{Evaluation of application effect of 3D interactive visual teaching platform}

\subsection{Research object}

The purpose of application effect research is to explore the real situation of the application of the three-dimensional interactive visual teaching platform in teaching, and to understand the satisfaction and recognition of the three-dimensional visual resource platform by teachers and students in the teaching activities. Taking the future classroom as the application platform, the students in the first year of high school are the research objects, and the questionnaires are used to collect information. A total of 83 students participated in the survey. The experimental group is 42 people; the control group is 41 people. 


\subsection{Analysis of research results}

The questionnaire uses a five-point scale, each of which contains five options: "completely disagree, disagree, general, agree, and fully agree". To deeply and comprehensively understand the application of students' acceptance and satisfaction for 3D visual teaching resources, some charts are used for analysis and summary.

The survey results of the distribution of students' interest in biology are shown in Figure 3.

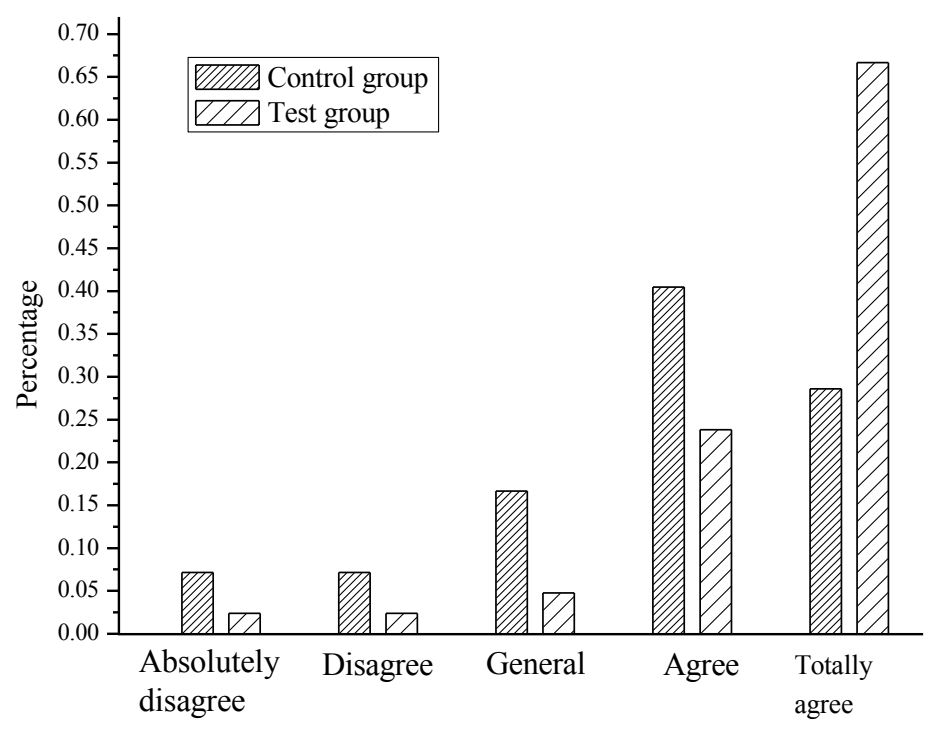

Fig. 3. Distribution of students' interest in learning biology

The study of the distribution of students' interest in biology is mainly to investigate the acceptance degree of students in the traditional classrooms and visual resource classrooms. The results show that $30.95 \%$ of the students in the traditional classroom are not interested in the teaching in the classroom and occupy a considerable proportion in a class. This is very unfavorable for the implementation of education and teaching activities, and it is necessary to use relevant auxiliary means to improve this phenomenon. The use of 3D visualization resources to "master amino acids" in biology teaching can improve students' interest in learning biology (the percentage of students who like biology increases from $69.05 \%$ to $90.4 \%$, a total increase of $21.4 \%$ ). It shows that contextualized and gamified 3D visualization resources are conducive to stimulating students' interest in learning, help to change the way of teaching, and change students' learning habits and learning strategies. When presenting abstract concepts, teachers should actively design and make three-dimensional visual education resources, assist teaching activities, and improve students' participation.

The survey results of the willingness to use the resource platform are shown in Figure 4. 
The survey results of the willingness to use resource platform indicate that the threedimensional visualization resources are helpful to students' learning to a certain extent. In the experimental group, 39 students are willing to use the resource platform for learning.

The results of the survey on the auxiliary effects of 3D visualization resources are shown in Figure 5.

By investigating whether 3D visualization resources are helpful for students to learn knowledge, $92.86 \%$ of students believe that using $3 \mathrm{D}$ visualization resources is helpful for learning knowledge. $7.14 \%$ of students believe that the use of $3 \mathrm{D}$ visualization resources to help learning knowledge is not much different from traditional teaching resources.

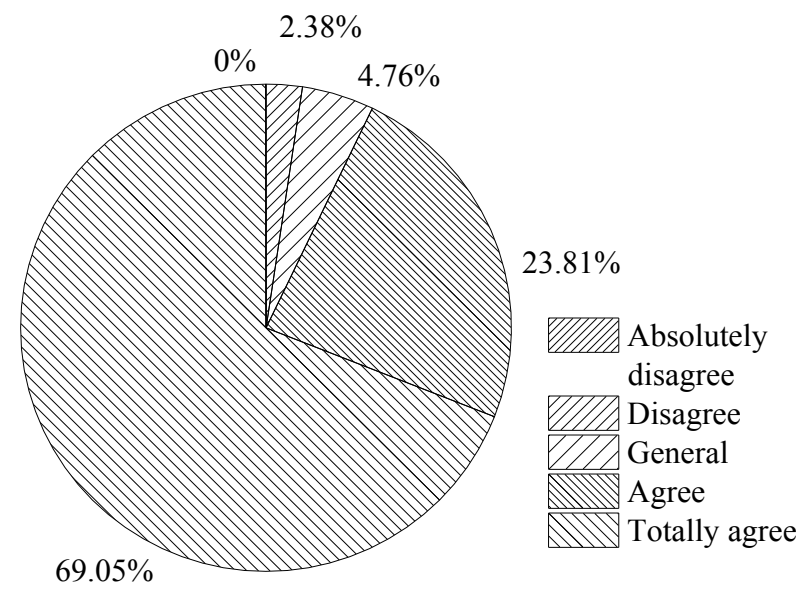

Fig. 4. Willingness to use the resource platform

$7.14 \%$

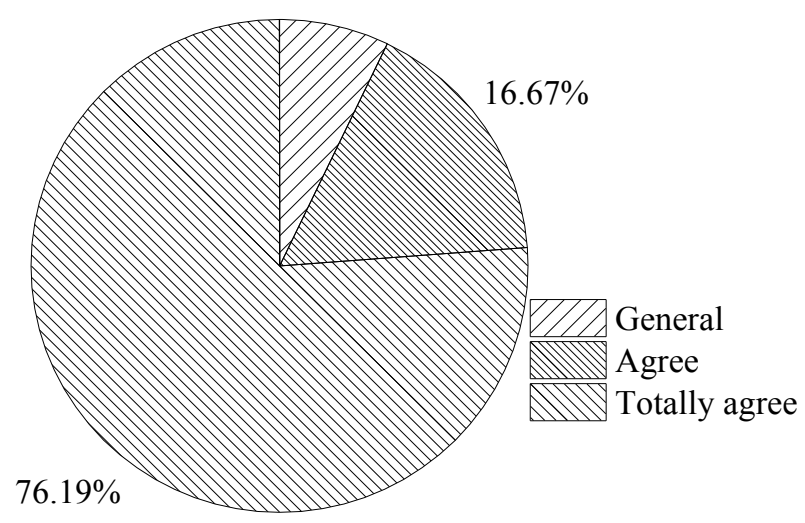

Fig. 5. Auxiliary effects of $3 \mathrm{D}$ visualization resources 
The survey effect of the interactive application of resources is shown in Figure 6.

Through the analysis of the effect of the $3 \mathrm{D}$ visualization resource platform in Figure 6 , the user experience directly affects the learning effect and the acceptance of the resource during the use process. After investigation, it is found that the design of the interaction of the resource platform still has certain weaknesses, and further modifications are needed for the resources.

The student's mastery of the knowledge points is shown in Figure 7.

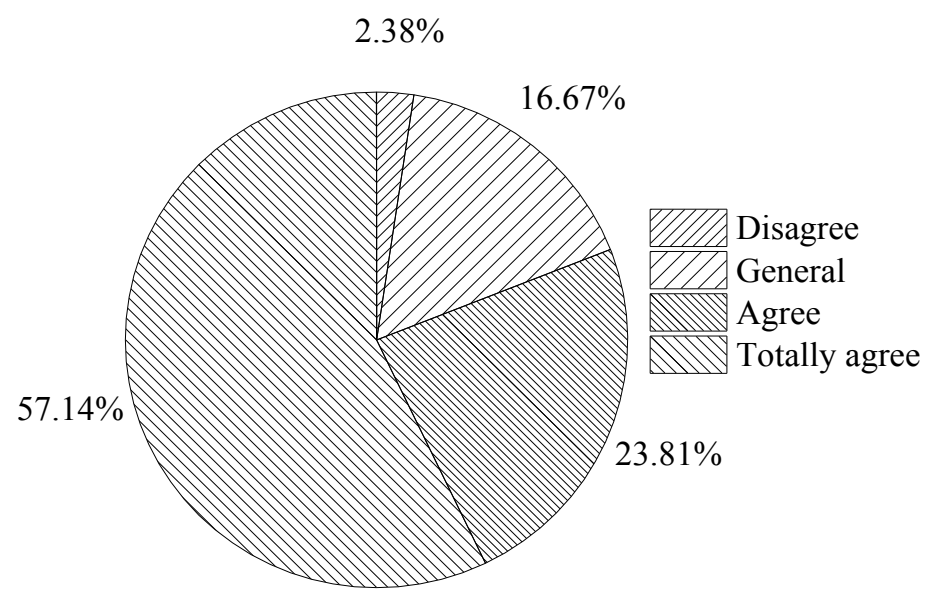

Fig. 6. Interactive application of resources

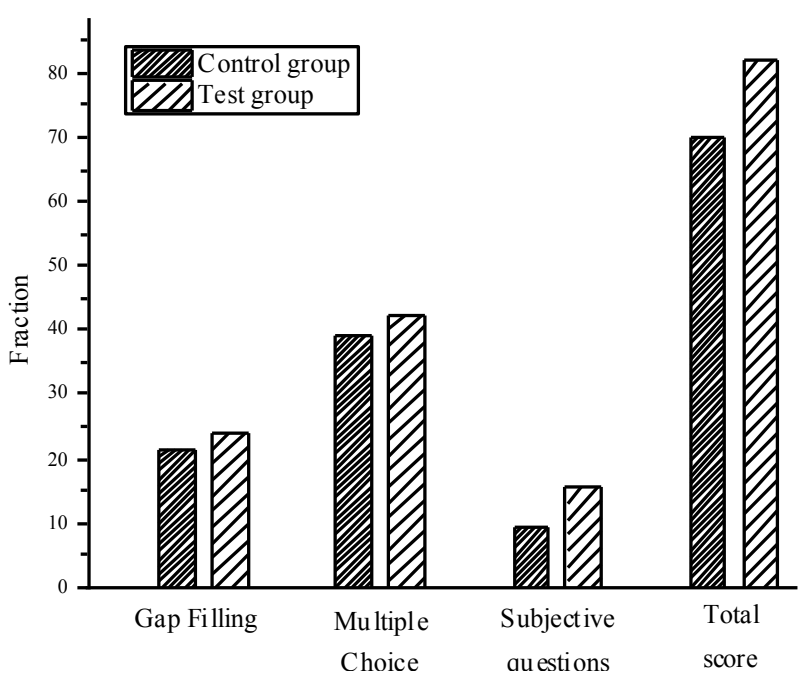

Fig. 7. Students' mastery of knowledge points 
Through the analysis of the students' mastery of the knowledge points in Figure 7, it is found that the use of 3D visualization resources in the teaching process can help students quickly grasp the knowledge points compared to the general classroom. Students learn knowledge through gamification, which is not easy to forget and is conducive to learning transfer.

\section{Conclusion}

By studying the problems existing in the design of 3D visualization resources in the teaching scene, combined with the specific knowledge points, the design scheme of 3D visualization resources is proposed, and the production process is also proposed, combined with specific development tools for production and applied it in the classroom. The steps of production of 3D visualization resources in the teaching scene are constructed, and each process is discussed in depth with specific production tools to verify that the proposed production process is feasible. Then the teaching design scheme with the application of $3 \mathrm{D}$ visualization resource is proposed, and the process is tested. Through questionnaires and interviews, it is found that the use of 3D visualization resources in the teaching scene can effectively improve students' interest and improve academic performance. Therefore, the application design proposed in this study is reasonable.

\section{$7 \quad$ Reference}

[1] Ma, X., Sun, R., Cheng, J., Liu, J., Gou, F., \& Xiang, H., et al. (2016). Fluorescence aggregation-caused quenching versus aggregation-induced emission: a visual teaching technology for undergraduate chemistry students. Journal of Chemical Education, 93(2), 345350. https://doi.org/10.1021/acs.jchemed.5b00483

[2] Mott, T. (2017). Teaching rounds: a visual aid to teaching internal medicine pearls on the wards, first edition. Family Medicine, 49(1), 68.

[3] Welsby, P. D. (2016). The neurophysiology of failed visual perceptions: some impli-cations for medical teaching. Postgraduate Medical Journal, 92(1084), 74. https://doi.org/10.1136/ postgradmedj-2015-133806

[4] Wong, V. S., \& Kellogg, M. A. (2017). Teaching neuroimages: a spiritual visual hallu-cination from a right parieto-occipital seizure: ictal guardian angel. Neurology, 88(11), e101. https://doi.org/10.1212/WNL.0000000000003709

[5] Traschütz, A., Hattingen, E., \& Klockgether, T. (2018). Teaching neuroimages: distinct visual anosognosia after serial lesions of meyer loop and the lateral geniculate body. Neurology, 91(1), e94-e95. https://doi.org/10.1212/WNL.0000000000005744

[6] Hansen, S. J. R., Mensah, F. M., \& Gordon, P. (2016). Confchem conference on interac-tive visualizations for chemistry teaching and learning: a multimodal examination of visual problem solving. Journal of Chemical Education, 93(6), págs. 1148-1149. https://doi.org/10.1021/acs.jchemed.5b00549

[7] Ferreira, M., Garcia, M. A., Handel, I. G., Breheny, C. R., \& Gow, A. G. (2018). Urine dipstick precision with standard visual and automated methods within a small animal teaching hospital. Veterinary Record. https://doi.org/10.1136/vr.104841 
[8] Bolognese, M., Von, A. H., \& Jordi, F. (2018). Teaching neuroimages: visual loss as a rare complication of mechanical thrombectomy. Neurology, 90(4), e355. https://doi.org/10.1212/WNL.0000000000004863

[9] Saterbak, A., Moturu, A., \& Volz, T. (2018). Using a teaching intervention and cali-brated peer review ${ }^{\mathrm{TM}}$ diagnostics to improve visual communication skills. Annals of Biomedical Engineering, 46(3), 1-12. https://doi.org/10.1007/s10439-017-1946-X

[10] Maruthappu, M., Sykes, M., Green, B. L., Watson, R., Gollop, N. D., \& Shalhoub, J., et al. (2017). Implementation of a teaching programme to improve doctors' awareness of dvla guidelines: a multicentre study. Postgraduate Medical Journal, 93(1096), 71-75. https://doi.org/10.1136/postgradmedj-2015-133744

[11] Renard, D., Hampton, J., Keita, M., \& Freitag, C. (2018). Teaching neuroimages: multimodality imaging of carotid web. Neurology, 90(17), e1541. https://doi.org/10.1212/ WNL.0000000000005359

[12] Kaplowitz, K., Yazdanie, M., \& Abazari, A. (2017). A review of teaching methods and outcomes of resident phacoemulsification. Survey of Ophthalmology, 63(2). https://doi.org/10.1016/j.survophthal.2017.09.006

[13] Kim, B. Z., Patel, D. V., Mckelvie, J., Sherwin, T., \& Mcghee, C. N. (2017). The auck-land cataract study ii: reducing complications by preoperative risk stratification and case allocation in a teaching hospital. American Journal of Ophthalmology, 181. https://doi.org/10.1016/j.ajo.2017.06.014

[14] Warner, E., \& Corbridge, R. (2018). A technique for teaching and photodocumentation of direct endoscopic rigid oesophagoscopy. Clinical Otolaryngology. https://doi.org/10.1111/ $\underline{\text { coa. } 13079}$

\section{Authors}

Dongmei Xia, Jing Li, and Liang Zhou are with Chongqing Institute of Engineering, Chongqing, 400056, China and the Chinese Culture Animation Research and Development Communication Center, Chongqing, 400056, China (e-mail: dongmeixia2193@21cn.com).

Article submitted 17 September 2018. Resubmitted 28 September 2018. Final acceptance 16 October 2018. Final version published as submitted by the authors. 